\title{
ABSORPTION OF LEUCINE, ALANINE AND LYSINE FROM THE RUMEN
}

\author{
T. VeRESEgyháZY ${ }^{1 *}$, Hedvig FÉBeL ${ }^{2}$ and Ágnes RIMANóCZY ${ }^{1}$ \\ ${ }^{1}$ Department of Physiology and Biochemistry, Faculty of Veterinary Science, \\ Szent István University, H-1400 Budapest, P.O. Box 2; Department of Physiology, \\ Research Institute of Animal Breeding and Nutrition, Herceghalom, Hungary
}

(Received June 23, 2000; accepted October 30, 2000)

The absorption of three amino acids (leucine, alanine and lysine) from the washed, closed rumen was studied in a short-term $(75 \mathrm{~min})$ experiment in situ. The concentration of leucine and alanine did not change in the rumen during the experiment, while that of lysine continuously decreased, and $40 \%$ of the total lysine placed in the rumen was absorbed during the experimental period. The rate of absorption decreased in proportion to the fall of amino acid concentration.

Key words: Amino acids, leucine, alanine, lysine, absorption, rumen

The organic components of feeds undergo substantial transformation in the rumen due to the effect of symbiotic microorganisms. Dietary proteins are degraded to peptides and amino acids by microbial proteases. The rate of protein degradation greatly depends on the composition of the microflora, microfauna and on the quality of dietary protein. Earlier we found that in vitro the rate of protein degradation was also influenced by the amino acid concentration. If the incubation mixture contained free amino acids in a concentration of $12 \mathrm{mmol} / \mathrm{l}$ and $24 \mathrm{mmol} / \mathrm{l}$, the rate of casein degradation decreased by $10 \%$ and $50 \%$, r espectively, as compared to when the incubation mixture did not contain free amino acids (Veresegyházy et al., 1993). However, protein degradation does not end with the formation of peptides and amino acids, since the released amino acids undergo an intensive deamination process. The bacteria can synthesise amino acids from free ammonia as a nitrogen source. The composition of the amino acid pool available for symbionts greatly determines the intensity of the deamination process. If methionine and valine constitute the only amino acid source for the symbionts of the rumen, their degradation will be of a higher rate than if the same were available for the microorganisms in the form of amino acid mixtures (Chalupa, 1976). The concentration of free amino acids in the rumen content varies in the period between two feedings. The highest concentration can be measured in the 2 nd or 3rd hour after feeding, and total concentration of the

*E-mail: tveres@univet.hu; Fax: +36 (1) 478-4165 
amino acids may exceed $6-10 \mathrm{mmol} / 1$ (Kolb, 1974). If the activity of deaminases was inhibited by avoparcin, the free amino acid quantity of the rumen content i ncreased to values as high as $14.3 \mathrm{mmol} / \mathrm{l}$ (Froetschell et al., 1983).

As regards the further fate of free amino acids, much knowledge has been gathered on their microbial utilisation, deamination and passage towards the abomasum. However, little is known on whether they are absorbed through the rumen wall and, if yes, what the rate and the characteristics of that transport pr ocess are like. In this experiment, the possibility of the absorption of alanine (Ala), leucine (Leu) and lysine (Lys) was studied in situ.

\section{Materials and methods}

Three British Milk ewes (average body weight: $85 \mathrm{~kg}$ ) were used in this experiment. First a rumen fistula was prepared surgically on each animal, then the opening of the fistula was closed with a Bar Diamond 8C type cannula (P.O. Box 60, Bar Diamond Lane, Parma, ID 83660-0060). The experiments were started after the animals' full recovery, in the 6th week after the operation.

At the beginning of the experiment the animals were put in a chute, and the rumen content was collected into a container through the opening of the fi stula. The rumen content was kept under anaerobic conditions at $39{ }^{\circ} \mathrm{C}$ throughout the experiment. The forestomachs were washed with body-warm tap-water until the effluent became clear. This usually required 5-6 cycles of washing. Subs equently the modified version of the apparatus developed by Engelhardt and Sallmann (1972) for the isolation of rumen was put in place. The essence of the modification is that the apparatus was fitted up with two inflatable rubber ba 1loons rather than one, to hold in position the closing apparatus to be placed into the ostium reticuloomasicum; thus, the closing apparatus could not move in any direction during the experiment. The diameter of the closing cylinder was i ncreased to $35 \mathrm{~mm}$ from the original $20 \mathrm{~mm}$ to ensure more secure fixation. As we could not fix in the oesophagus that part of the apparatus which served for draining off saliva, a known amount of Cr-EDTA was added to the amino acid solution in order to measure liquid volume changes due to salivary secretion during the experiment. (Preparation of Cr-EDTA: $28.4 \mathrm{~g} \mathrm{CrCl}_{3} \times 6 \mathrm{H}_{2} \mathrm{O}+40 \mathrm{~g}$ $\mathrm{Na}_{2}$ EDTA in 0.51 volume was cooked for $1 \mathrm{~h}$. Excess EDTA was removed by $8 \mathrm{ml} 1 \mathrm{~mol} / 1 \mathrm{CaCl}_{2}$ solution. The $\mathrm{pH}$ was adjusted to a value between 6 and 7 by the addition of $\mathrm{NaOH}$, and the solution was made up to 11 .)

After isolation of the rumen the opening of the fistula was closed. The sa mpling tube was placed at the middle part of the cannula applied for the time of the experiment, next to a plastic tube that served for inflating the rubber balloon of the closing device. With a $400-\mathrm{ml}$ syringe, $2800 \mathrm{ml}$ physiological $\mathrm{NaCl}$ solution was injected, and then in $100 \mathrm{ml}$ volume $4.5 \mathrm{~g}$ amino acid was placed into the rumen. 
This was followed by the injection of $2 \mathrm{ml} \mathrm{Cr-EDTA}$ and then the liquid volume was made up to $3000 \mathrm{ml}$. Theoretically the calculated concentration of Leu, Ala and Lys was consistently $34.2,50.4$ and $30.8 \mathrm{mmol} / 1$ at the start of the experiment. Compounding of the liquid required approximately $5 \mathrm{~min}$. This was followed by the taking of the sample (0-min sample) intended for the determination of the a ctual initial amino acid and Cr-EDTA concentrations. Further samples were taken at $5,15,30,45,60$ and $75 \mathrm{~min}$ after taking the 0 -min sample. The samples were i mmediately frozen to $-20{ }^{\circ} \mathrm{C}$ and stored at that temperature until processed. After the last sampling, the liquid content of the rumen was removed, the rumen content $\mathrm{r}$ eplaced and the cannula closed.

The $\mathrm{Cr}$ content of the samples was determined by an atomic absorption method immediately after filtration (Atom Absorption Spectr ophotometer, AA$6701 \mathrm{~F}$ Shimadzu), using acetylene-air gas mixture with flame atomisation, at $357.9 \mathrm{~nm}$ (L233-24NB Hollow-Cathode lamp).

The concentration of amino acids was determined, after derivatisation with o-phthaldialdehyde/2-mercaptoethanol reagent, by isocratic elution on a reversed phase Hypersil 5 ODS (BST, Budapest) $100 \times 4 \mathrm{~mm}$ column, with a highperformance liquid chromatography instrument (HPLC: Liquochrom Model 2010, Labor MIM Budapest, Liquopump 312/1, OE 320 injector with a 20- $\mu 1$ sample application loop, OE 308 spectrophotometer). The mobile phase was a methanol : phosphate buffer $(0.025 \mathrm{~mol} / \mathrm{l} ; \mathrm{pH} 7.2)$ mixture of varying ratio. The composition of the eluent used for the measurement of the three amino acids is shown in Table 1 . The detection wavelength was $330 \mathrm{~nm}$, and the flow rate of the eluent was $0.8 \mathrm{~cm}^{3} / \mathrm{min}$ (Lindroth and Mopper, 1979). The chromatograms were evaluated with the help of a LabChrom (Chemotron Ltd., Budapest) co mputerised data collection and processing system.

Using the measured Cr-EDTA concentration, the liquid content of the $\mathrm{r} u$ men was calculated by a simple dilution formula as follows:

$$
\begin{aligned}
& \qquad \mathrm{V}_{3}=\frac{\mathrm{V}_{1} \times \mathrm{c}_{1}+\mathrm{V}_{2} \times \mathrm{c}_{2}}{\mathrm{c}_{3}} \\
& \text { where } \mathrm{V}_{1}=3000 \mathrm{ml} \\
& \mathrm{V}_{2}=2 \mathrm{ml} \text { (the volume of Cr-EDTA) } \\
& \mathrm{V}_{3}=\text { liquid content of the rumen at the time of sampling }(\mathrm{ml}) \\
& \mathrm{c}_{1}=\text { original Cr concentration of the injected liquid }(\mathrm{ppm}) \\
& \mathrm{c}_{2}=\text { Cr concentration of the Cr-EDTA stock solution }(\mathrm{ppm}) \\
& \mathrm{c}_{3}=\text { Cr concentration measured at the time of sampling }(\mathrm{ppm})
\end{aligned}
$$

The amino acid content of the rumen was calculated on the basis of the liquid volume and the concentration. For each animal, the amino acid quantity measured in the 0 -min sample was taken as $100 \%$, and this served as a basis for determining the percentile value of absorption. 


\section{Table 1}

Composition of the eluent used for the measurement of amino acid concentrations

\begin{tabular}{lcc}
\hline Amino acid & $\begin{array}{c}\text { Phosphate buffer (\%) } \\
(0.025 \mathrm{~mol} / \mathrm{l}, \mathrm{pH} 7.2)\end{array}$ & Methanol (\%) \\
\hline Ala & 51 & 49 \\
Leu & 45 & 55 \\
Lys & 40 & 60 \\
\hline
\end{tabular}

\section{Results}

Rumen fluid content increased continuously and usually at a steady rate during the experiments. The average rate of increase was $800 \mathrm{ml}$ in $75 \mathrm{~min}$.

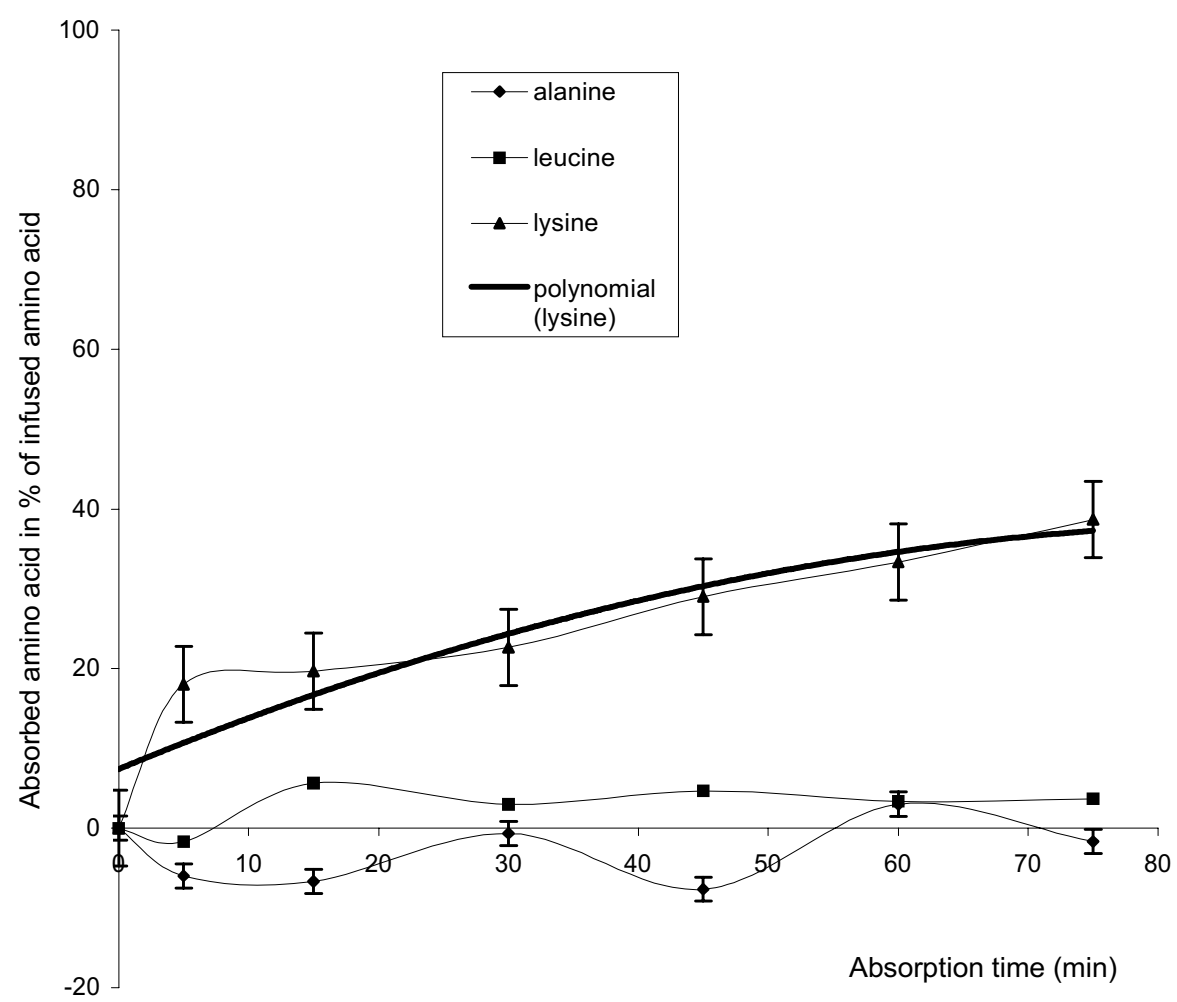

Fig. 1. Absorption of alanine, leucine and lysine from washed, closed ovine rumen 
The concentration of Leu and Ala was practically unchanged in the rumen content during the 75-min experiment. It appears that Lys can be absorbed across the rumen wall, as in the average of experiments performed on three animals $40 \%$ of the Lys infused into the rumen was lost from the rumen liquor in $75 \mathrm{~min}$.

The graph showing the average values clearly demonstrates that the o btained absorption values were very close to the polynomial trend line fitted to the measurement points by the Excel programme $\left(y=-0.0037 x^{2}+0.6768 x+\right.$ 7.3943). Only the values obtained at 5 min showed a relatively substantial devi ation from the above equation (Fig. 1).

\section{Discussion}

Very few data have been found in the literature on whether or not amino acids are absorbed through the rumen wall. One hour after feeding there is a si gnificant increase in the concentration of free amino acids in the rumen liquor. Somewhat later this is followed by the rise of blood plasma free amino acid co ncentration (Leibholz, 1969). The highest concentration of free amino acids in the rumen liquor can be measured in the 2nd or 3rd hour after feeding (Kolb, 1974). The relative proportions of free amino acids in the blood plasma were found to be independent of the protein and amino acid composition of the diet (Leibholz, 1969). According to in vitro studies, glycine is transported into the ruminal ep ithelium. That transport could be suspended with 2,4-dinitrophenol and indole acetate, which suggests that an active transport process may be involved (Chand et al., 1968). Leibholz (1971) also used an in vitro preparation to study the tran sport of L-histidine and glycine. Both of these amino acids crossed the ruminal epithelium, and the rate of their transport was concentration $d$ ependent.

The results of our present study indicate that not all the amino acids are transported through the rumen wall. The concentration of the two apolar amino acids (Leu, Ala) remained practically unchanged during the experiment. This i ndicates that these amino acids either were not absorbed or the rate of their twodirectional transport across the rumen wall was roughly the same. Lys, an amino acid with a positive charge, showed very rapid absorption at the beginning of the experiment, when amino acid concentration was relatively high. Subsequently, its absorption rate decreased in proportion to the fall of amino acid concentration in the rumen liquor. The initial rapid absorption also explains the marked diffe $\mathrm{r}$ ences frequently found between the 0-min values even if the concentration of amino acids infused into the rumen is identical: namely, the time required for the procedures to be performed after the infusion of amino acids is never the same in two experiments. 


\section{Acknowledgements}

The authors thank the Hungarian Scientific Research Fund (OTKA) and the NKB Committee of the Faculty of Veterinary Science, Szent István University, Budapest for financial support provided for the study (project numbers OTKA T 030303 and NKB2000-KUT-4-B/006), and László Veresegyházy for preparation of the closing device and cannula used in the experiment.

\section{References}

Chalupa, W. (1976): Degradation of amino acids by the mixed rumen microbial population. J. Anim. Sci. 43, 828-834.

Chand, D., Varma, S. D. and Kushwaha, R. P. S. (1968): Active transport of glycine by rumen epithelium of betal goats. J. Dairy Sci. 51, 1420-1422.

Engelhardt, v. W. and Sallmann, H. P. (1972): Resorption und Sekretion in Pansen des Guanakos (Lama guanacoe). Zbl. Vet. Med. A 19, 117-132.

Froetschell, M. A., Croom, W. J. Jr., Caskins, H. R., Leonard, E. S. and Whitacre, M. D. (1983): Effects of avoparcin on ruminal propionate production and amino acid degradation in sheep fed high and low fiber diets. J. Nutr. 113, 1355-1362.

Kolb, E. (1974): Lehrbuch der Physiologie der Haustiere. Gustav Fischer Verlag, Jena, 316 pp.

Leibholz, J. (1969): Effect of diet on the concentration of free amino acids, ammonia and urea in the rumen liquor and blood plasma of the sheep. J. Anim. Sci. 29, 628-633.

Leibholz, J. (1971): The absorption of amino acids from the rumen of the sheep II. The transfer of histidine, glycine, and ammonia across the rumen epithelium in vitro. Aust. J. Agric. Res. 22, 647-653.

Lindroth, P. and Mopper, K. (1979): High performance liquid chromatographic determination of subpicomole amounts of amino acids by precolumn fluorescence derivatization with ophthaldialdehyde. Analyt. Chem. 51, 1667-1674.

Veresegyházy, T., Fekete, S. and Hegedűs, M. (1993): Factors influencing ruminal bacterial activity I. Effect of end-product concentration on proteolytic activity. J. Anim. Physiol. Anim. Nutr. 70, 1-5. 